\title{
Impact of Strength of Human Resource Management System on Perceived Organizational Support
}

\author{
$\operatorname{Li~Sun}^{1} \&$ Chanchai Bunchapattanasakda ${ }^{1}$ \\ ${ }^{1}$ School of Management, Shinawatra University, Pathum Thani, Thailand \\ Correspondence: Chanchai Bunchapattanasakda, School of Management, Shinawatra University, 99 Moo 10 \\ Bang Toey, Sam Khok District, Pathum Thani 12160, Thailand. E-mail: alaskatornado@gmail.com
}

Received: January 12, 2018

doi:10.5539/ijbm.v14n3p60
Accepted: February 14, $2019 \quad$ Online Published: February 19, 2019

URL: https://doi.org/10.5539/ijbm.v14n3p60

\begin{abstract}
Among the various influencing factors of organizational performance, HRM system strength and perceived organizational support are two important factors which focus on employee perception. In modern business management, human resource management runs through the whole process of business management. Effective HR system can influence employee perception, understanding and acceptance of HRM practices, which in turn influence employee's attributions to organizational behaviours and thereby influence employee attitudes and behaviours. Besides, organizational commitment to employees can promote employee's positive attributions and feedback through job satisfaction and hard work. So far, there has been a plethora of researches on variables related to HRM system strength and perceived organizational support. However, there is a lack of the research on the relationship between the two variables. Therefore, this paper studied the impact of HRM system strength on perceived organizational support, based on a survey of 508 front-line employees in China. Research findings showed that there is a significant positive relationship between overall HRM system strength and perceived organizational support, between three dimensions of HRM system strength and two dimensions of perceived organizational support. This result can help researchers understand the relationship chain between HRM system strength, perceived organizational support and organizational performance.
\end{abstract}

Keywords: implications, perceived organizational support, strength of human resource management system

\section{Introduction}

Perceived organizational support has been considered as an important factor that influence employee attitudes (McCarthy et al., 2013; He \& Pham, 2014; Xu et al., 2017), behaviors (Lee \& Peccei, 2011; Yu et al., 2017; Zheng \& Hu, 2018) and organizational performance (Bell \& Menguc, 2002; Shoss et al., 2013; Kurtessis et al., 2015). In view of this, there is a growing body of literature on the antecedent variables of perceived organizational support. Among the factors that influence perceived organizational support, human resource management practices are considered as an important factor and have received substantial empirical studies (Ghani, 2009; Ahmed \& Nawaz, 2015; Lin, 2018). Many companies also stated that specific human resource management measures are very important. However, well-designed HRM practices cannot necessarily make employees have an effective perception of organizational support. The reason is that in the process of information transmission, noise and other interferential factors can lead to information leakage, distortion and deformation. Then employees may make subjective judgments based on their own understanding of reality and guide their own behavior. The interpretation of individual differences in employees can lead to differentiated employee behavior, loyalty, and job satisfaction (Guzzo \& Noonan, 1994). Thus, we can say that effective transmission of HRM information is very important for guiding employee judgement and related behavior. Besides, the concept of strength of HRM system reflects the extent to which employees effectively perceive HRM information. Therefore, this research attempts to study whether strength of HRM system can influence employee perception of organizational support so as to help researchers better understand the relationship between human resource management and employee attitudes \& behaviors, and even organizational performance. 


\section{Literature Review}

\subsection{Strength of Human Resource Management System}

Strength of human resource management system was first proposed by Bowen and Ostroff (2004) as a situation in which "unambiguous messages are communicated to employees about what is appropriate behavior". The authors identified a set of characteristics that allow HRM system to create strong situations and regarded these characteristics as the process by which a consistent message about HRM content can be sent to employees. These characteristics includes visibility, understandability, legitimacy of authority, relevance, instrumentality, validity, consistent HRM messages, agreement among principal HRM decision makers, fairness. Besides, Bowen and Ostroff stated that the nine features could build distinctiveness, consistency and consensus that a strong situation needed.

Distinctiveness of the situation generally refers to features that allow the information to stand out in the environment, thereby capturing attention and arousing interest. It can be fostered by four characteristics: visibility, understandability, legitimacy of authority, and relevance. Visibility refers to the degree to which HR practices are salient and readily observable. Understandability refers to a lack of ambiguity and ease of comprehension of HRM content. Legitimacy of authority refers to an authority situation when the HRM function is perceived as a high-status, high-credibility function and activity. Relevance refers to a situation when individuals perceive HRM practices relevant to their important goals, and also the power of influencing agents to help individuals achieve relevant goals.

Consistency of the situation generally refers to establishing an effect over time and modalities whereby the effect occurs each time the entity is present, regardless of the form of the interactions. Three features can help establish consistent relationships over time, people, and contexts: instrumentality, validity, and consistent HRM messages. Instrumentality refers to establishing an unambiguous perceived cause-effect relationship in reference to the HRM system's desired content-focused behaviors and associated employee consequences. Validity refers to the consistency of HRM practices between they purport to do and what they actually do so as to create a strong situation. Consistent HRM messages means the consistency of messages between what senior managers say and what employees perceive, among HRM practices themselves, the strong agreement among employees as to what is expected of them and what they expect of the organization in return.

Consensus of the situation refers to the agreement among employees regarding the relationship between an event and its effect. Two characteristics can foster consensus among employees and influence whether individuals perceive the same effect with respect to the entity or situation in question: agree met among principal HRM decision makers, and fairness. Agreement among principal HRM decision makers refers to the agreement among these message senders on the design of HRM practices of the organization. Fairness of the HRM system is a composite of employees' perceptions of whether HRM practices adhere to the principles of delivering three dimensions of justice: distributive, procedural, and interactional.

\section{2 Perceived Organizational Support}

Levinson (1965) stated that the understanding of organizational support stemmed from the personified traits of the organization in the minds of employees, and reflected the organization's legal, moral, and financial responsibility through the actions of the organizational agents. Organizational procedures, norms, and organizational culture are constantly reflected in the role of the organization's agents and act on each employee. Through organizational agents, employees see happy and unpleasant treatment from the organization as a concrete basis for how organizations view their contributions and whether the organization cares about their welfare.

Eisenberger et al. (1986) defined perceived organizational support as employees' global beliefs concerning the extent to which the organization values their contributions and cares about their well-being. Eisenberger and his colleagues also called "perceived organizational support" as "employer commitment." McMillin (1997) complemented the concept proposed by Eisenberger, and stated that organizational support should include, in addition to the organization's concern and respect for employees, tool support such as equipment, information, personnel, etc., necessary for the job staff to work better.

Ling et al. (2006) used Maslow's hierarchy of demands theory to divide the important needs of employees into three categories in the context of Chinese culture: the material needs, organizational respect and recognition, sense of accomplishment and self-realization. These three types of needs require the organization's support for job, value recognition and employee benefits which are regarded as three major dimensions of organizational support perceived by Chinese employees. This perception comes from three different aspects of work motivation. 
That is, paying attention to the interests of employees is to meet the need for survival. Value recognition is the need to satisfy self-esteem, and job support is to meet the needs of growth. This is very similar to Adelford's theory of ERG needs (existence needs, relatedness needs and growth needs).

Chen (2006) divided perceived organizational support into two dimensions, four dimension, and nine dimensions. The two dimensions include emotional support and instrumental support. The four dimensions include emotional support, instrumental support, superior support and colleague support. Nine dimensions include work support, value, competence and ambition, interpersonal support, welfare and job security, tolerance and understanding, fair and reasonable support, concern for respect, career development. Yuan (2017) revised the three-dimension scale of Ling et al. (2006) and expanded perceived organizational support into five dimensions. The five dimensions are respectively job support, value recognition, care about interests, emotional support and developmental support.

\subsection{HRM System Strength and Perceived Organizational Support Relationship}

Bowen and Ostroff (2004) stated that HRM system can influence employee attitudes and behaviors, as well as organizational outcomes, through employee interpretations of the work climate. According to attribution theory, when the human resource management system is perceived as high distinctiveness, consistency and consensus, in other words, when the HRM system strength is high, a strong situation will be created, and employees will be fully informed of organizational features, based on which employees will perform accurate and positive attributions. Besides, the higher the human resource management system strength is, the clearer the information is through the strong situation created within the organization. According to social exchange theory, when the organization's human resource management practices are effectively perceived by employees, employees will feel the organizational concern. There are some empirical studies which showed that HRM system strength is the antecedent variable of perceived supervisory support ( $\mathrm{Li}$ et al., 2011). The idea of personification of the organization regards supervisory support as an important part of organizational support (Levinson, 1965). Moreover, perceived supervisory support is considered as one of the main components of perceived organizational support (Bao \& Liu, 2011). Therefore, this research develops a conceptual framework, with dimensions of HRM system strength as independent variables, with dimensions of perceived organizational support as dependent variables.

\subsection{Research Hypothesis}

There is a significant relationship between HRM system strength and perceived organizational support.

\section{Research Methods}

This research made a survey of 508 individual employees in Henan Province, China to test the impact of HRM system strength dimensions on perceived organizational support. In the questionnaire, demographics characteristics include the information about gender, age, education, working period, company nature, industry, and position. This study adopted the HRM system strength scale of Delmotte et al. (2011) which was developed by strictly following the theoretical model of Bowen and Ostroff (2004) and has been verified in Belgium context. HRM system strength scale in this research consists of three dimensions: "distinctiveness", "consistency" and "consensus", among which the "distinctiveness" dimension includes 10 items, the "consistency" dimension includes 9 items and the "consensus" dimension includes 5 items. Perceived organizational support scale was adopted from Chen's (2006) research which is based on the scale of Eisenberger, including ten items, of which seven items measured emotional support, three items measured instrumental support. In order to ensure the translation accuracy and content validity of the questionnaire, this research made some revisions of the questionnaire according to HR expert opinions, translation, back-translation, and pilot study before the final questionnaires were issued. The main data analysis methods in this research are reliability analysis, t-test, one-way ANOVA and multiple linear regression analysis.

\section{Findings and Discussion}

\subsection{Reliability Test}

Reliability test results showed that overall HRM strength scale (Cronbach $a=0.962$ ) and overall perceived organizational support scale (Cronbach $\mathrm{a}=0.971$ ) have good reliability, because their Cronbach a coefficient is greater than 0.9. Besides, three subscales of HRM system scale have high reliability, with distinctiveness scale (Cronbach $a=0.831$ ), consistency scale (Cronbach $a=0.961)$, consensus scale (Cronbach $a=0.951$ ); two subscales of perceived organizational support have high reliability, with emotional support (Cronbach $a=0.964$ ), and instrumental support (Cronbach $\mathrm{a}=0.902$ ). This indicates that respondents have a high perception and understanding of the questions in the questionnaire and have a good applicability in Chinese context. 


\subsection{The Impact of Demographics on HRM system strength and Perceived Organizational Support}

According to t-test and one-way ANOVA analysis, we found that only position has a significant impact on perceived organizational support (Table 1), while other demographic variables have no significant impact on perceived organizational support.

Table 1. Difference of Position in HRMSS and POS

\begin{tabular}{lccccccccccc}
\hline & Mean 1 & Mean 2 & Mean 3 & Mean 4 & Mean 5 & Mean 6 & Mean 7 & Mean 8 & Mean 9 & $\mathrm{F}$ & Sig. \\
& $\mathrm{N}=45$ & $\mathrm{~N}=56$ & $\mathrm{~N}=87$ & $\mathrm{~N}=61$ & $\mathrm{~N}=56$ & $\mathrm{~N}=58$ & $\mathrm{~N}=38$ & $\mathrm{~N}=78$ & $\mathrm{~N}=29$ & & \\
\hline DS & 3.7244 & 3.5036 & 3.4195 & 3.6197 & 3.5554 & 3.5293 & 3.6974 & 3.6795 & 3.4931 & 1.258 & .263 \\
$\mathrm{CN}$ & 3.9056 & 3.6161 & 3.5374 & 3.7951 & 3.8482 & 3.7112 & 3.9868 & 3.9231 & 3.6121 & 1.387 & .200 \\
$\mathrm{CS}$ & 3.8778 & 3.6339 & 3.5862 & 3.8402 & 3.6830 & 3.7026 & 3.9737 & 3.9327 & 3.7241 & .873 & .540 \\
ES & 3.9029 & 3.5470 & 3.3721 & 3.7689 & 3.6877 & 3.6953 & 3.9258 & 3.9062 & 3.5231 & 1.949 & .051 \\
$\mathrm{IS}$ & 4.0742 & 3.7330 & 3.5291 & 3.9131 & 3.8984 & 3.9309 & 4.0353 & 4.1412 & 3.8848 & 2.057 & $.038^{*}$ \\
\hline
\end{tabular}

Note. 1 = Sales Staff; $2=$ Production Staff; $3=$ General Administrative Staff; $4=$ Logic Staff; $5=$ Human Resource Staff; $6=$ Financial/Accountant Staff; 7 = Marketing Staff; $8=$ R\&D Staff; 9 = Others. * indicates significant at 0.05 level (2-tailed test)

From the Table 1, we can see that respondents with different positions have significant difference only in perceiving instrumental support of the organization. Moreover, the scores of R\&D staff are significantly higher in "instrumental support" dimension than employees with other positions. This indicates that R\&D staff of Henan enterprises have much more significant perception of good working environment, facilities, training, people and information support from their organizations. A possible explanation may be that the development and innovation of an organization depend on the efforts of R\&D staff to a large extent. Besides, Henan provincial government and local governments have issued many policy bonuses to attract high-tech talents, and motivate the innovation of enterprises.

\subsection{Hypothesis Test}

In this section, position is a categorical variable which is conversed to dummy variables for entering the regression equation. There are two steps. First, dummy variable was forced to enter the regression equation. Second, three dimensions of HRM system strength were introduced to regression equation to test the significant influence of HRM system strength on perceived organizational support. Regression analysis results showed that HRM system strength has a significant relationship with perceived organizational support, and also there is a significant relationship between dimensions of HRM system strength and dimensions of perceived organizational support (Table 2, Table 3, Table 4).

Table 2. Regression analysis of HRMSS on perceived organizational support

\begin{tabular}{|c|c|c|c|c|c|c|c|}
\hline & & \multicolumn{3}{|c|}{ Step 1} & \multicolumn{3}{|c|}{ Step 2} \\
\hline & & Beta & $\mathrm{t}$ & Sig. & Beta & $\mathrm{t}$ & Sig. \\
\hline Demographics & Pos 1 & .084 & 1.254 & .211 & .050 & 1.782 & .075 \\
\hline \multirow[t]{7}{*}{ Variables } & Pos 2 & -.008 & -.118 & .906 & .014 & .468 & .640 \\
\hline & Pos 3 & -.074 & -.919 & .359 & -.033 & -.980 & .328 \\
\hline & Pos 4 & .054 & .741 & .459 & .024 & .799 & .425 \\
\hline & Pos 5 & .034 & .482 & .630 & .044 & 1.501 & .134 \\
\hline & Pos 6 & .039 & .548 & .584 & .045 & 1.498 & .135 \\
\hline & Pos 7 & .079 & 1.228 & .220 & .027 & 1.019 & .309 \\
\hline & Pos 8 & .114 & 1.468 & .143 & .055 & 1.697 & .090 \\
\hline HRM System Strength & & & & & .901 & 48.855 & $.000 * * *$ \\
\hline \multirow{5}{*}{ Model Summary } & $\mathrm{R}^{2}$ & & .032 & & & .830 & \\
\hline & $\mathrm{F}$ & & $2.030^{*}$ & & & $275.627 * * *$ & \\
\hline & $\mathrm{P}$ & & .041 & & & .000 & \\
\hline & $\triangle R^{2}$ & & .032 & & & .814 & \\
\hline & $\triangle \mathrm{F}$ & & 2.030 & & & 273.597 & \\
\hline
\end{tabular}

Note. ${ }^{* * *}$ indicates significant at the 0.001 level (2-tailed); ** indicates significant at the 0.01 level (2-tailed); * indicates significant at the 0.05 level (2-tailed); Beta as standardized Beta. 
In the Table 2, after introducing demographics variables, the regression equation only explained $3.2 \%$ variances, the exploratory power is weak, though regression equation is significant. After introducing HRM system strength, regression equation is extremely significant, and the independent variables explained $83 \%$ variances of perceived organizational support. Besides, the value of $\mathrm{F}$ significantly increased and the explanatory power of regression equation increased by $81.4 \%$. Regression coefficient showed that HRM system strength has a significant positive influence on perceived organizational support (Beta $=0.901, \mathrm{P}=0.000$ ).

Table 3. Regression analysis of HRMSS dimensions on emotional support of POS

\begin{tabular}{|c|c|c|c|c|c|c|c|}
\hline & & \multicolumn{3}{|c|}{ Step 1} & \multicolumn{3}{|c|}{ Step 2} \\
\hline & & Beta & $\mathrm{t}$ & Sig. & Beta & $\mathrm{t}$ & Sig. \\
\hline Demographics & Pos 1 & .097 & 1.448 & .148 & .046 & 1.971 & $.049 *$ \\
\hline \multirow[t]{7}{*}{ Variables } & Pos 2 & .007 & .095 & .925 & .023 & .942 & .347 \\
\hline & Pos 3 & -.051 & -.639 & .523 & -.010 & -.375 & .708 \\
\hline & Pos 4 & .072 & .989 & .323 & .032 & 1.282 & .200 \\
\hline & Pos 5 & .046 & .653 & .514 & .039 & 1.565 & .118 \\
\hline & Pos 6 & .049 & .687 & .492 & .046 & 1.865 & .063 \\
\hline & Pos 7 & .096 & 1.482 & .139 & .030 & 1.349 & .178 \\
\hline & Pos 8 & .125 & 1.599 & .111 & .049 & 1.810 & .071 \\
\hline \multirow[t]{4}{*}{ HRM System Strength } & DS & & & & .117 & 3.373 & $.001 * * *$ \\
\hline & $\mathrm{CN}$ & & & & .175 & 5.876 & $.000 * * *$ \\
\hline & $\mathrm{CS}$ & & & & .696 & 27.012 & $.000 * * *$ \\
\hline & $\mathrm{R}^{2}$ & & .030 & & & .885 & \\
\hline \multirow[t]{4}{*}{ Model Summary } & $\mathrm{F}$ & & 1.949 & & & $346.205 * * *$ & \\
\hline & $\mathrm{P}$ & & .051 & & & .000 & \\
\hline & $\triangle \mathrm{R}^{2}$ & & .030 & & & .855 & \\
\hline & $\triangle \mathrm{F}$ & & 1.949 & & & 344.256 & \\
\hline
\end{tabular}

Note. $* * *$ indicates significant at the 0.001 level (2-tailed); ** indicates significant at the 0.01 level (2-tailed); $*$ indicates significant at the 0.05 level (2-tailed); Beta as standardized Beta.

In the Table 3, after introducing demographics variables, the regression equation explained 3\% variances, the exploratory power is weak, regression equation is not significant. After introducing three dimensions of HRM system strength, regression equation is very significant, and the independent variables explained $88.5 \%$ variances of emotional support. Besides, the value of $\mathrm{F}$ significantly increased and the explanatory power of regression equation increased by $85.5 \%$. Regression coefficient showed that all three dimensions of HRM system strength have a significantly positive influence on emotional support of perceived organizational support, among which, consensus has the greatest influence on instrumental support (Beta $=0.696, \mathrm{P}=0.000$ ), followed by consistency $(\mathrm{Beta}=0.175, \mathrm{P}=0.000)$ and distinctiveness $(\mathrm{Beta}=0.117, \mathrm{P}=0.001)$. 
Table 4. Regression analysis of HRMSS dimensions on instrumental support of POS

\begin{tabular}{llllllll}
\hline & \multicolumn{5}{c}{ Step 1 } & \multicolumn{5}{c}{ Step 2 } \\
\hline Demographics & & Beta & $\mathrm{t}$ & Sig. & Beta & $\mathrm{t}$ & Sig. \\
Variables & Pos 1 & .048 & .720 & .472 & -.001 & -.023 & .982 \\
& Pos 2 & -.043 & -.601 & .548 & -.029 & -.766 & .444 \\
& Pos 3 & -.120 & -1.502 & .134 & -.084 & -1.951 & .052 \\
& Pos 4 & .008 & .114 & .910 & -.029 & -.744 & .458 \\
& Pos 5 & .004 & .054 & .957 & -.008 & -.207 & .836 \\
& Pos 6 & .013 & .183 & .855 & .008 & .214 & .830 \\
& Pos 7 & .036 & .552 & .581 & -.026 & -.742 & .458 \\
HRM System Strength & Pos 8 & .083 & 1.067 & .286 & .012 & .286 & .775 \\
& $\mathrm{DS}$ & & & & .114 & 2.105 & $.036^{*}$ \\
& $\mathrm{CN}$ & & & & .211 & 4.550 & $.000^{* * *}$ \\
& $\mathrm{CS}$ & & & & .570 & 14.199 & $.000^{* * *}$ \\
& $\mathrm{R}^{2}$ & & .032 & & & .720 & \\
& $\mathrm{~F}$ & & $2.057^{*}$ & & & $116.011^{* * *}$ & \\
& $\mathrm{P}$ & & .038 & & & .000 & \\
& $\triangle \mathrm{R}$ & & .032 & & & .688 & \\
& $\triangle \mathrm{F}$ & & 2.057 & & & 113.954 & \\
\hline
\end{tabular}

Note. ${ }^{* * *}$ indicates significant at the 0.001 level (2-tailed); ${ }^{* *}$ indicates significant at the 0.01 level (2-tailed); $*$ indicates significant at the 0.05 level (2-tailed); Beta as standardized Beta.

In the Table 4, after introducing demographics variables, the regression equation explained $3.2 \%$ variances, the exploratory power is weak, though regression equation is significant. After introducing three dimensions of HRM system strength, regression equation is still significant, and the independent variables explained $72 \%$ variances of instrumental support. Besides, the value of $\mathrm{F}$ significantly increased and the explanatory power of regression equation increased by $68.8 \%$. Regression coefficient showed that all three dimensions of HRM system strength have a significantly positive influence on instrumental support of perceived organizational support, among which, consensus has the greatest influence on instrumental support (Beta=0.570, $\mathrm{P}=0.000)$, followed by consistency $(\mathrm{Beta}=0.211, \mathrm{P}=0.000)$ and distinctiveness $(\mathrm{Beta}=0.114, \mathrm{P}=0.036)$.

\subsection{Discussion}

Wang (2012) stated that strategic human resource management practices can be considered as a communication channel between employers and employees, and are the medium in which the organization transmits information to employees. And employees generate corresponding attitudes and behaviors based on information acceptance, decoding and interpretation. In view of this, the level of employee perceptions is closely related to the degree of visibility and understandability of human resource management information. Bowen and Ostroff (2004) stated that HRM practices are supported by top management support through investments in human resources, HR practices, involvement of HRM professionals in strategic planning process, it indicates these HRM practices are credible. Besides, top management support can convey the information that the organization values human resources and make organizational support more visible. The Congruence between both individual goals and organizational goals can also help foster employee willingness to use his relevant capabilities to achieve organizational goals, which in turn will influence individual goals by rewards, promotion, etc. Then the realization of the employee's individual goals will make the employees perceive the concern and attention of the organization. Therefore, higher distinctiveness can lead to higher employee perception of organizational support.

Consistency requires organizations to establish consistent links between human resources management practices and time, people, and context. Siehl (1985) stated that individuals desire consistency in organizational life, and the lack of consistency in "double-bind" communication can lead to particularly intense cognitive dissonance. In order to evade this issue, the unambiguous information transmission of HRM system's desired behaviors and associated employee consequences can strengthen employee perception of support and incentives from the organization when employees performed appropriate behaviors for achieving strategic objectives of the organization. Besides, employee perception of organizational support can be influenced by the consistency between HRM practices and implementation, the compatibility and stability in the signals sent by HRM practices because consistent HRM messages and the effective implementation of HRM practices help form a shared perception and positive interpretations of organizational support. Thus, higher consistency can result in higher employee perception of organizational support. 
Consensus among employees results when they view message senders (top management, human resource managers, and line managers) strongly consistent in human resource management. Bowen and Ostroff (2004) stated that as more employees "see" the practice and perceive that top decision makers agree on it, consensus can be facilitated. Further, Lado and Wilson (1994) stated that integration and close interactions among HRM professionals, mangers and top managers foster the exchange of tacit knowledge for the formulation and implementation of an organizational strategy and HRM system that reflect the firm's strategic direction. These integrations among decision makers can help promote relevance by clearly identifying important goals and means to goal attainment, in this process, employees can perceive organization's value on employee efforts and concerns about their welfare. Thus, higher consensus can result in higher employee perception of organizational support.

\section{Conclusion}

\subsection{Summary}

This research discussed two important antecedent variables of organizational performance and confirmed the significant relationship between HRM system strength and perceived organizational support. Chang and Tao (2006) stated human resource management is an employer-led labor relationship model, and it built a community of interests of employers and employees and achieved a win-win situation in organizational performance and employee benefits through human resource management practices. For employees, through downward communication, human resource management will inevitably convey positive information to employees, such as respect and concern for employees, facilities, information, training and people support for employees. Therefore, we can see that a strong HRM system can foster a shared perception of organizational support. More specifically, a HRM system which is high in distinctiveness, consistency, and consensus can enhance clarity of interpretation in organizational support, thereby allowing for similar "cognitive maps" to develop among employees.

\subsection{Implications}

This research identified the good applicability of Delmotte's HRM system strength scale in Chinese research, enriched the outcome variable of HRM system strength and antecedent variable of perceived organizational support. The research tested the impact of HRMSS dimensions on perceived organizational support, which allows for researchers to know the extent the three dimensions affect employee perception of perceived organizational support, and also can help researchers better understand the relationship mechanism between HRM system strength, perceived organizational support and organizational performance. Besides, this research can help Chinese enterprises learn the characteristics of effective HRM system, then guide appropriate employee attitudes and behaviors and promote organizational performance.

\subsection{Limitations}

This study only analyzed the relationship between HRM system strength and perceived organizational support which are two important influencing factors of organizational performance, there is a lack of a complete research on HRM system strength-perceived organizational support—organizational performance. Besides, the respondents come from various industries, so whether research findings have a generalizability in different industries needs to be further verified. Moreover, this study only surveyed the front-line employees, which cannot represent managers' views on HRM system strength of the organization.

\subsection{Suggestions for the Future Research}

Future research can consider collecting the information about organizational performance, identify indicators that reflect organizational performance, and then study the relationship between HRM system strength, perceived organizational support and organizational performance. Besides, future research can restrict the research sample to a certain industry, select a certain number of leading companies in the industry to conduct sampling surveys and examine the hypothesis confirmed by this study. In addition, under the premise of obtaining the consent of the management personnel, future research can make a questionnaire survey of managers at all levels to understand different employees' perception and acceptance of human resource policies and practices. Furthermore, future research can make a comparative research on the relationship between employee perception in HR function and organizational performance in the regions which have different levels of economic development and government policies.

\section{References}

Ahmed, I., \& Nawaz, M. M. (2015). Antecedents and outcomes of perceived organizational support: A literature survey approach. Journal of Management Development, 34(7), 867-880. http://dx.doi.org/10.1108/JMD-09-2013-0115 
Bao, G. M., \& Liu, Q. (2011). Research on multi-dimensional conceptual models of perceived organizational support. Research Management, 2, 160-168. http://dx.doi.org/10.19571/j.cnki.1000-2995.2011.02.021

Bell, S. J., \& Menguc, B. (2002). The Employee-organization relationship, organizational citizenship behaviors, and superior service quality. Journal of Retailing, 78(2), 131-146.

Bowen, D. E., \& Ostroff, C. (2004) Understanding HRM-firm performance linkages: The role of the "strength" of the HRM system. Academy of Management Review, 29(2), 203-221.

Chang, K., \& Tao, W. Z. (2006). Human resource management and labor relations adjustment. China Human Resources Development, 8, 4-9. http://dx.doi.org/10.16471/j.cnki.11-2822/c.2006.08.001

Chen, Z. X. (2006). The effect of sense of organizational support of knowledge employees on job performance and turnover intention (Unpublished doctoral dissertation). Huazhong University of Science and Technology, China.

Chen, Y., Qi, Z. F., \& Tang, G. Y. (2015). Empirical research on the relationship between human resource management strength and job performance. East China Economic Management, 29(12), 151-157. http://dx.doi.org/10.3969/j.issn.1007-5097.2015.12.027

Cunha, R. C., \& Cunha, M. P. (2004). Impact of strategy, HRM strength and HRM bundles on innovation performance and organizational performance (Unpublished doctoral dissertation). Universidade Nova de Lisboa, Lisbon.

Delmotte, J., Winne, S. D., \& Sels, L. (2011). Toward an assessment of perceived HRM system strength: Scale development and validation. The International Journal of Human Resource Management, 1, 1-26. http://dx.doi.org/10.1080/09585192.2011.579921

Eisenberger, R., Huntington, R., Hutchison, S., \& Sowa, D. (1986). Perceived organizational support. Journal of Applied Psychology, 71(3), 500-507. http://dx.doi.org/10.1037/0021-9010.71.3.500

Ghani, N. A. (2009). Antecedents of perceived organizational support. Canadian Social Science, 5(6), 33-42.

Guzzo, R. A., \& Noonan, K. A. (1994). Human Resource practices as communications and the psychological contract. Human Resource Management, 33(3), 447-462.

Hauff, S., Alewell, D., \& Hansen, N. K. (2017). HRM system strength and HRM target achievement-Toward a broader understanding of HRM processes. Human Resource Management, 56(5), 715-729.

He, H., \& Pham, H. Q. (2014). Perceived organizational support and organizational identification: Joint moderating effects of employee exchange ideology and employee investment. International Journal of Human Resource Management, 25(20), 2772-2795. https://doi.org/10.1080/09585192.2014.908315

Kurtessis, J. N., Eisenberger, R., Ford, M. T., Buffardi, L. C., Stewart, K. A., \& Adis, C. S. (2015). Perceived organizational support: A meta-analytic evaluation of organizational support theory. Journal of Management, 20(10), 1-31. http://dx.doi.org/10.1177/0149206315575554

Lado, A. A., \& Wilson, M. C. (1994). Human resource systems and sustained competitive advantage: A competency-based perspective. Academy of Management Review, 19(4), 699-727.

Lee, J., \& Peccei, R. (2011). Discriminant validity and interaction between perceived organizational support and perceptions of organizational politics: A temporal analysis. Journal of Occupational and Organizational Psychology, 84(4), 686-702. http://dx.doi.org/10.1348/096317910X511197

Levinson, H. (1965). Reciprocation: The relationship between man and organization. Administrative Science Quarterly, 9, 370-390. http://dx.doi.org/10.2307/2391032

Lin, N. N. (2018). Research on the relationships among developmental human resources practices, perceived organizational support and turnover intention of knowledge workers in enterprises (Unpublished master's thesis). Hebei University of Economics and Business, China.

Ling, W. Q., Yang, H. J., \& Fang, L. L. (2006). Perceived organizational support of the employees. Journal of Psychology, 38(2), 281-287.

McCarthy, A., Cleveland, J. N., Hunter, S., Darcy, C., \& Grady, G. (2013). Employee work-life balance outcomes in Ireland: A multilevel investigation of supervisory support and perceived organizational support. International Journal of Human Resource Management, 24(6), 1257-1276. http:// doi.org/10.1080/09585192.2012.709189

McMillin, R. (1997) Customer satisfaction and organizational support for service providers (Unpublished 
doctoral dissertation). University of Florida, Gainesville.

Sels, L., Winne, S. D., Maes, J., Delmotte, J., Faems, D., \& Forrier, A. (2006). Unravelling the HRM-performance link: Value-creating and cost-increasing effects of small business HRM. Journal of Management Studies, 43(2), 319-342. https://doi.org/10.1111/j.1467-6486.2006.00592.x

Shoss, M., Eisenberger, R., Restubog, S., \& Zagenczyk, T. (2013). Blaming the organization for abusive supervision: The roles of perceived organizational support and supervisor's organizational embodiment. Journal of Applied Psychology, 98(1), 158-168. https://doi.org/10.1037/a0030687

Siehl, C. J. (1985). After the founder: An opportunity to manage culture. In P. Frost, L. Moore, M. Louis, C. Lundberg, \& J. Martin (Eds.), Organizational culture (pp. 125-140). Beverly Hills, CA: Sage.

Wang, X. Y. (2012). The research on relationship between strategic human resource management, employee trust and sharing knowledge (Unpublished doctoral dissertation). Soochow University, China.

Xu, J., Zhao, L., Wei, L. H., \& Shen, Y. M. (2017). The impact of perceived organizational support on organizational identification: The mediating effects of perceived insider status and organization-based self-esteem. Psychological Exploration, 37(3), 275-282.

Yuan, P. P. (2017). Research on post-90s staff's turnover intention based on perceived organizational (Unpublished master's thesis). Chongqing Jiaotong University, China

Yu, K., Liu, X. Y., \& Huang, Y. H. (2017). Research on the influence of visionary leadership on employees' voice behavior: The role of organizational support and challenge-based stress assessment. Modern Management Science, 5, 106-108.

Zheng, C. J., \& Hu, P. P. (2018). Research on the relationship between organizational support and Bootleg innovation in Internet firms-The mediating effect of job satisfaction. West Forum on Economy and Management, 29(2), 72-80.

\section{Copyrights}

Copyright for this article is retained by the author(s), with first publication rights granted to the journal.

This is an open-access article distributed under the terms and conditions of the Creative Commons Attribution license (http://creativecommons.org/licenses/by/4.0/). 